\title{
sciendo
}

DOI 10.2478/sbe-2019-0014

SBE no. 14(1) 2019

\section{CLASHING PERSPECTIVES ON SUSTAINABLE DEVELOPMENT}

\author{
PANȚA Nancy Diana \\ Lucian Blaga University of Sibiu, Romania
}

\begin{abstract}
:
We live in a world characterised by speed owing mainly to technology. Everything happens at a faster pace, from the way production and consumption takes place to the way the environment is degrading. Henceforth, sustainable development appeared in response to these consequences. However, considering that we are discussing the topic of sustainable development for over three decades now, it is probably time to bring it forward in another way and try to better understand it through opposing perspectives. Therefore, the present paper explores differing views on the discussed topic, and analyses sustainable development in relation to other similar terms, trying to provide a clear meaning of the concept. More, it looks to provide a own interpretation of sustainable development, and intends to bring forward some of the most popular and disputing models surrounding it.
\end{abstract}

Key words: Sustainable Development, Sustainability, Theoretical Framework

\section{Introduction}

Over the past three decades, we witnessed environmental degradation and growing inequalities in development worldwide. Sustainable development appeared in response to the negative consequences taking place on Planet Earth, but not only, being more and more popularized both in practice and among scholars. However, with all the buzzword created around it, the concept left a few blanks in the minds of many and appeared to ask more questions than provide answers. This was mainly owing to its complexity and to the fact that it has been highly debated. Still, with all the efforts on conceptualizing and operationalizing sustainable development, much of the debate is still ongoing, even to this day.

Undoubtedly, sustainable development is a slippery concept, which allows many interpretations and views to co-exist. However, it is not seldom that such views clash in perspectives and the result is often translated into confusion and into a misuse of terms.

Consequently, the present paper depicts an effort to overcome arbitrary interpretations and shed a light on the concept of sustainable development by breaking it down and bringing opposing views face to face through an analysis of available literature. 


\section{Breaking Down Sustainable Development}

Sustainable Development (SD) is a concept that has faced criticism since its emergence. Some say that it is an elusive concept with a contradictory and ambiguous meaning (O'Riordan, 1996), while others think that SD is a cliché (Lélé, 1991), embedded in almost everything in our lives.

The meaning of SD has remained vague during the years, which opened new ways for opposing views to support their positions, either for the continuation of growth economics or for no-growth economics (Fergus and Rowney, 2005), but not only. Therefore, instead of providing answers, SD created even more questions.

The international scientific community debated the concept throughout several decades, which helped to develop it into a holistic concept. Today, SD is known to take in environmental, social and economic aspects (Duran et al., 2015), but also global problems such as the ability to produce and maintain.

SD encompasses two elements: on one hand, there is the term 'sustainable' which stands for durability, and on the other hand, there is 'development' which aims at extensiveness (Duran et al., 2015). Not rarely, sustainability has been used interchangeably with SD, but there is also a distinction made between the two (Waas et al., 2011), as they are used with different connotations. Sustainability tackles systems, while SD addresses human needs and well-being (Feil and Schreiber, 2017). According to Hove (2004), SD is a process contributing to achieving sustainability, namely the ultimate longterm goal. In other words, sustainability is the integer and SD is part of it, where sustainability follows the results obtained by using SD strategies. Therefore, the sustainability of systems depends on the process of SD (Sartori et al., 2014). SD process consists in actions linked to managerial, financial, strategic and technical skills which help leading to sustainability (Dempsey et al., 2011).

Differentiation is also made between the concept of 'SD' and the term 'sustainable'. Although the terms 'sustainable' and 'development' represent a whole and a particular concept taken together, 'sustainable' can be applied and integrated to an array of fields ranging from sustainable business to sustainable agriculture, sustainable education and not only (Waas, et al., 2011).

Even the meaning of the term 'sustainable' is controversial as a result of conflicting views (Blewitt, 2008), which have their roots in different currents such as (1) biology and the conservation of natural resources, (2) ecology and the preservation of ecosystems, (3) economy and economic growth without harming the environment, and (4) sociology with societal development (Feil and Schreiber, 2017). Due to the complex relations that it attracted, the term has also sparked a number of critiques, such as being polysemantic (Mebratu, 1998; Slimane, 2012), controversial (Yolles and Fink, 2014), confusing (Newton and Freyfogle, 2005), insufficiently explained (Sartori et al., 2014), misunderstood (Ekins et al., 2003) and has even been considered useless (Morris, 2012) or just a popular slogan (Slimane, 2012). However, Banon Gomis et al. (2011) consider that the term 'sustainable' is more than a mere a tendency or fashion. More, criticism to the use of the term 'sustainable' also arose in the context of dynamic systems, indicating that the notion is not static (Prugh and Assadourian, 2003) and that it has originated in the capacity of systems 
to adapt to the impacts on environment and not only caused by humanity (Yolles and Fink, 2014).

In a time when environmental damage is caused by human activities, many support the idea that SD provides direction for progress at societal level (Fergus and Rowney, 2005). Still, the questions regarding how and if such progress is achieved remain. Therefore, SD is viewed as a flexible concept, open for interpretation. Because of this, many agreed that it attracted opportunities for irreconcilable opinions to find common ground (Redclift, 2014; Barbosa et al., 2014). Two of such antagonistic views include capitalism and ecology, which were brought together by SD (Jabareen, 2008). Therefore, $\mathrm{SD}$ is able to simultaneously maintain economic relations and fix the ecological crisis. Still, one considerable challenge that awaits to be solved by SD is given by the paradox of the concept itself, between the environment which represents the 'sustainable' aspect and the economic facet which represents the 'development' (Feil and Schreiber, 2017).

In response to the challenges that awaits SD, the following actions can be undertaken in order to contribute to solving the gap between the existing global supply and demand: societal demands which are placed on Earth to be reduced and/or resources to be supplemented (Williams and Millington, 2004). There are a number of ways of answering to these and they consist in (1) weak sustainability, (2) strong sustainability and (3) moderate sustainability.

Weak sustainability stresses the importance of aggregate capital. It involves the need to replenish the stock of resources and it explains that man-made or manufactured capital can be used as an alternative to natural capital (Emas, 2015). Weak sustainability can be achieved through the development of renewable resources, the development of substitutes for resources that are non-renewable, a more effective use of current resources, respectively through the development of technologies capable of addressing resource depletion (Williams and Millington, 2004).

Opposite to weak sustainability is strong sustainability. Also known as deep ecology', it involves the reduction of the pressure we are placing on Earth, through a decrease of consumption. It counts on us adapting to Earth, instead of expecting it to fully meet our needs, considering its unique finite features of natural resources (Klarin, 2018).

Last but not least, there is moderate sustainability, placed along the continuum, between the extremities of weak and strong sustainability. Moderate sustainability combines elements of the two approaches (Williams and Millington, 2004).

\section{Defining Sustainable Development}

Even though there are various discourses on SD circulating for several decades now, there is no clear definition of the concept (Duran et al, 2015). It has been used both as a campaigner at global level to promote equality among nations at global level, but also by corporations to grace their actions (Redclift, 2006).

Although it may appear simple, the concept of SD includes underlying complexities and confusions. Over 300 definitions and different interpretations were provided by literature on SD until the end on the twentieth century (Dobson, 1996). Still, even with so many definitions that abound, the most referred to is the one proposed by the Brundtland 
Report (Dernbach, 2003). The definition states that 'SD is meeting the needs of present without compromising the ability of future generations to meet their needs' (WCED, 1987). In other words, SD implies long-term holistic planning based on strategies that refer to ecology and biodiversity. Initially, SD was regarded by Brown (1981) as relating to society, in which the needs of the members are satisfied without compromising the survival chances of the generations to come.

There are a few complements made by WCED (1987) on SD, which indicate that it represents a global agenda, calling for change and for new behavioural norms in the interest of all, at all levels. Therefore, SD encourages programs of development from a local to a global scale applied in a variety of scenarios, ranging from businesses to governmental institutions, industry, and civil society, where the interests and aspirations of each are portrayed through SD lenses (Kates et al., 2005). SD does not provide a specific recipe, though, for saving the environment from depletion and degradation, but acts instead as an approach that is driving change in humanity's behaviour. According to the Brundtland Report, SD addresses intergenerational equity through the conservation of resources for the benefit of future generations. This feature of SD goes beyond environmental policies, which touch the internalization of externalities concerning environmental degradation (Emas, 2015).

Although this world view encountered in the Brundtland definition is contested by many (Williams and Millington, 2004), it acknowledges the starting point of the concept. This resides in a paradox of environmental nature, where a mismatch is considered between the demand from the Planet Earth and its ability of supplying (Cahill, 2001).

The Brundtland report states that in light of SD, humanity faces limitations due to a number of factors that include the current state of technology, the way environmental resources are managed and the biosphere's ability to take in human activities (WCED, 1987). After the Brundtland report was published, many became interested in understanding and interpreting SD (Kates et al., 2005). US National Research Council, in its published work entitled Our Common Journey (1999) provided a clearer view on SD and noted what ought to be sustained and what ought to be developed. Therefore, it identified nature with its ecosystems and biodiversity as needing to be sustained along with life support like resources, ecosystem services and environment, and lastly, community with elements such as culture, places and groups. Regarding what needs to be developed, attention was headed towards people (life expectancy, equity, education, child survival, equal opportunity), economy (consumption, wealth, productive services) and societies (states, regions, social capital, institutions).

The environmental problems caused lately by human activities require complex approaches, which led to increasing efforts of integrating multiple aspects under development, following the Brundtland definition. Pearce (1989) wrote that SD requires the creation of both economic and social systems to ensure that goals related to incomes rise, and that educational standards, health improvement and overall quality of life are met. Soon afterwards, Harwood (1990) noted that SD is itself a system with the ability to evolve on an indefinite period towards reaching increased efficiency of resource use and balancing this use with the environment for the benefit of humanity and other species. Lélé (1991) also tackled change in approaching SD, referring to it as a process in which 
intended changes can be repeated endlessly. Some argued that SD entails the way humanity should act in relation to nature, and that it ought to be responsible for today's and tomorrow's generations (Ayres, 1996). SD was also seen as a social building derived from economic development in the context of dynamic human population, integrated into ecosystems (Meadows, 2004).

Another point of view defined SD as a program aimed at changing the way the economic development takes place so that it can provide for all people basic quality of life while protecting the ecosystem (Vander-Merwe and Van-der-Merwe, 1999). More recent opinions highlighted that SD is a response to the modern western lifestyle and culture (Beck and Wilms, 2004). Sterling (2010) defines SD as a reconciliation between the environment and economy, headed towards human progress at global level and on a long term. SD was also regarded as a conscious process undertaken to avoid damages made upon environmental, social and economic spheres aiming for a prosperous and promising life (Banon Gomis et al., 2011). In the view of Marin et al. (2012), SD involves the ability of a system to run continuously and indefinitely without reaching resource depletion. Lately, literature on SD has placed more importance on human development, and as Barter and Russell (2012) wrote, the concept is about more than only saving the environment, but human survival. In their conception, SD refers to internalizing strategies for economic growth to be shared by all.

As we approach present days, views on SD begin to incorporate modern aspects. Besides integrating social, economic and environmental dimensions, technology is also taken into consideration by Ivascu (2013) as a support technique for maintaining systems stability, being balanced with the other components involved, without affecting the needs of the generations to come. More, Harlow et al. (2013) add that modernization is one of the main characteristics of SD, along with economic growth. Change has been mentioned in previous definitions of SD, but Barbosa et al. (2014) state that SD is a process of change that relies of social learning in the long run.

The element of 'change' is present in a number of views exposed above. This can be attributed to the fact that SD tackles not only development, but also needs, which change themselves accordingly. Consequently, it is unlikely that the needs of today's generation will be the same with those of future generations (Redclift, 2006). However, the question whether needs differ across different cultures remains (Redclift, 2006). More, how are societies supposed to behave in front of trade-offs when it comes to their needs? Does a society dealing with increased pollution have to put first material wealth? How can it decide the most sustainable course of action?

Besides these issues, it is adequate to try to provide a definition of SD considering the above meanings. Although the Brundtland definition remains of reference, SD approaches need to be adapted and brought to the modern days. A more extensive definition of SD would differentiate it from sustainability and would include technology, social learning and human development, together with economic growth and environmental protection. Therefore, in light of the above meanings, SD is a process which contributes to achieving sustainability by integrating economic, social, environmental and technological aspects through social learning, calling for change at all levels and aiming for quality of life on the long run. 
Table 1. Understandings of SD

\begin{tabular}{|c|c|c|}
\hline Author & Year & Understanding of SD \\
\hline WCED & 1987 & $\begin{array}{l}\text { SD addresses intergenerational equity through the } \\
\text { conservation of resources for the benefit of future } \\
\text { generations. It implies long-term holistic planning based } \\
\text { on strategies that refer to ecology and biodiversity. It } \\
\text { represents a global agenda, calling for change and for } \\
\text { new behavioural norms in the interest of all, at all levels. }\end{array}$ \\
\hline Pearce et al. & 1989 & $\begin{array}{l}\text { SD implies the creation of systems of economic and } \\
\text { social nature required to ensure that goals related to } \\
\text { incomes rise, educational standards, health improvement } \\
\text { and overall quality of life are met. }\end{array}$ \\
\hline Harwood & 1990 & $\begin{array}{l}\text { SD is a system with the ability to evolve on an indefinite } \\
\text { period towards reaching increased efficiency of resource } \\
\text { use for the benefit of humanity and other species. }\end{array}$ \\
\hline Lélé & 1991 & $\begin{array}{l}\text { SD is a process in which intended changes can be } \\
\text { repeated endlessly. }\end{array}$ \\
\hline Ayres & 1996 & $\begin{array}{l}\text { SD entails the way humanity should act in relation to } \\
\text { nature, being responsible for today's and tomorrow's } \\
\text { generations. }\end{array}$ \\
\hline Meadows & 1998 & $\begin{array}{l}\text { SD is a social building derived from economic } \\
\text { development in the context of dynamic human population, } \\
\text { integrated into ecosystems. }\end{array}$ \\
\hline $\begin{array}{l}\text { Vander-Merwe } \\
\text { and Van-der- } \\
\text { Merwe }\end{array}$ & 1999 & $\begin{array}{l}\text { SD is a program aimed at changing the way the economic } \\
\text { development takes place so that it can provide for all } \\
\text { people basic quality of life while protecting the ecosystem. }\end{array}$ \\
\hline Beck and Wilms & 2004 & $\begin{array}{l}\text { SD is a response to the modern western lifestyle and } \\
\text { culture. }\end{array}$ \\
\hline Sterling & 2010 & $\begin{array}{l}\text { SD is a reconciliation between the environment and } \\
\text { economy, headed towards human progress at global level } \\
\text { on a long term. }\end{array}$ \\
\hline $\begin{array}{l}\text { Banon Gomis et } \\
\text { al. }\end{array}$ & 2011 & $\begin{array}{l}\text { SD is a conscious process undertaken to avoid damages } \\
\text { made upon environmental, social and economic spheres } \\
\text { aiming for a prosperous and promising life. }\end{array}$ \\
\hline Marin et al. & 2012 & $\begin{array}{l}\text { SD involves the ability of a system to run continuously and } \\
\text { indefinitely without reaching resource depletion. }\end{array}$ \\
\hline $\begin{array}{l}\text { Barter } \\
\text { Russell }\end{array}$ & 2012 & $\begin{array}{l}\text { SD is about more than only saving the environment, but } \\
\text { about human survival, referring to internalizing strategies } \\
\text { for economic growth so that SD can be shared by all. }\end{array}$ \\
\hline Ivascu & 2013 & $\begin{array}{l}\text { SD is an integration of social, economic, environmental } \\
\text { and technological aspects for maintaining systems }\end{array}$ \\
\hline
\end{tabular}




\begin{tabular}{|l|l|l|}
\hline & & $\begin{array}{l}\text { stability, without affecting the needs of the generations to } \\
\text { come. }\end{array}$ \\
\hline Harlow & 2013 & $\begin{array}{l}\text { SD includes modernization as one of its main } \\
\text { characteristics, along with economic growth }\end{array}$ \\
\hline Barbosa et al. & 2014 & $\begin{array}{l}\text { SD is a process of change that relies of social learning on } \\
\text { the long run. }\end{array}$ \\
\hline
\end{tabular}

Source: Own interpretation according to cited sources

\section{Operationalising Sustainable Development}

Because of the complexity that SD entails, several models were proposed in order to simplify it. Therefore, it became common practice to try to make SD more understandable through a number of pillars. Not surprisingly, opinions differ when it comes to agreeing on which one is the most adequate model.

During its emergence, SD was mainstreamed as a concept that balanced three pillars, namely the economic, social and ecological pillars (Elkington, 1994). According to the proponent of the model, SD involves the achievement of the following three dimensions:

(1) Ecological, which promotes environmental protection, biodiversity conservation, emissions reduction and the use of resources in a rational manner. It seeks to improve the resource base and the quality of the environment using a long-term view.

(2) Social, through providing equal opportunities for members of society, protecting human rights, respecting cultural diversity and preserving social values. The human component aims to obtain socio-cultural stability by addressing social interactions and values of humanity (Dempsey et al., 2011).

(3) Economic pillar, which looks to create welfare in order to respond to essential needs such as food, water, jobs, income, sanitation and so on. It considers economic growth by maintaining the natural capital needed. In other words, the economic component seeks to ensure a maximum and continuous flow of goods, services, and income, in terms of a rational and efficient resource use by avoiding extreme imbalances among sectors. Therefore, it is responsible for minimising its negative impact on the environment.

$\mathrm{SD}$ is, nonetheless, a multidimensional process. In the above framework, also known as the Triple Bottom Line (TBL) or People-Planet-Profit approach, Elkington (1994) notes that the dimensions ought to be all sustainable and in balance for SD to be achieved. Obtaining a balance between the three components can be difficult, so every pillar has to respect the interest of the others (Klarin, 2018). Furthermore, the approach can prove particularly complex from the perspective of strong sustainability, where no substitute of natural capital is involved.

The three dimensions of the TBL do not refer to stakeholders participation, which has attracted criticisms, since some consider the involvement of stakeholders crucial to obtaining SD. The participation of stakeholders in the process of SD is considered vital (Holden et al., 2014) because of their ability to implement policies and not only. Consequently, the institutional/governance component was added as the fourth dimension 
(Waas et al., 2011). It follows to integrate environmental and economic aspects into decision making and administer the common interest of all through an enhanced public participation.

Some also suggested that culture should be included as an additional dimension. Yet, whether there should be less than three, three, or more dimensions, has not been agreed upon so far.

A set of dimensions was also proposed through the Brundtland Report. It provided four primary dimensions that included fundamental values such as protecting ecological sustainability, promoting equity both intergenerationally and at intragenerational level, and meeting basic human needs. Later on, Hoyer (2000) added a number of secondary dimensions, which referred to safeguarding the environment, protecting the intrinsic value of nature, responding to aspirations of an enhanced living standard and encouraging public participation. Primary dimensions are prioritised in front of secondary dimensions, meaning for instance that protecting the intrinsic value of nature is subordinate to meeting basic human needs. The model does not include economic growth as a primary dimension, which comes in contradiction to the TBL view. Instead, economic growth is seen as a means to fulfil the primary dimensions.

Prioritising and creating hierarchies among dimensions can lead to conflicts between them. According to Naess (1988), development must be ecologically sustainable before everything else in order to be sustainable. This view places weight on ecological sustainability, being also referred to as 'narrow sustainability' (Holden et al., 2014). The Brundtland model covers broader issues, and although it might cause conflicts among primary and secondary dimensions, there is no hierarchy created between primary dimensions. Because of the broader spectrum on SD, the approach is called 'broad sustainability'.

\section{Conclusion}

Sustainable development should be able to provide solutions on issues that affect the quality of life in the long run and integrate elements of social, economic, environmental and technological nature by relying on social learning and calling for change at all levels. However, although it attracted supporters ranging from institutions, to scholars and businesses, the applicability of the concept is in danger of remaining limited due to constraints given by its debatable nature and lack of understanding.

The results of the analysis indicated that there is a clear difference between sustainable development and sustainability, with sustainability being the ultimate long-term goal and sustainable development being the process contributing to achieving it. More, it showed that although late models of sustainable development are of reference, they need upgrading by integrating elements that are inherent, like stakeholders participation. Also, the analysis dismissed the idea of creating a hierarchy between primary dimensions due to the potential of causing conflicts between the building blocks of sustainable development and it questioned the required balance that needs to exist between components in relation to the strong sustainability perspective. 


\section{References}

Ayres, R., (1996), Statistical measures of unsustainability, Ecological Economics, Vol. 16, no. 3, pp. 239-255.

Banon Gomis, A., Parra, M., Hoffman, M., McNulty, R., (2011), Rethinking the Concept of Sustainability, Business and Society Review, Vol. 116, no. 2, pp. 171-191.

Barbosa, G., Drach, P., Corbella, O., (2014), A Conceptual Review of the Terms Sustainable Development and Sustainability, International Journal of Social Sciences, Vol. 3, no. 2.

Barter, N., Russell, S., (2012), Sustainable Development: 1987 to 2012 - Don't Be Naive, it's not about the Environment, Proceedings of the $11^{\text {th }}$ Australasian Conference on Social and Environmental Accounting Research, pp. 1-18.

Beck, U., Wilms, J. (2004): Conversations with Ulrich Beck, Polity Press, Cambridge.

Blewitt, J. (2008): Understanding sustainable development, Earthscan, London.

Brown, L. (1981): Building a Sustainable Society, Worldwatch Institute, Washington.

Cahill, M. (2001): Social policy and the environment, The Gildredge Press, Brighton.

Dempsey, N., Bramley, G., Power, S., Brown, C., (2011), The Social Dimension of Sustainable Development: Defining Urban Social Sustainability, Sustainable Development, Vol. 19, no. 5, pp. 289-300.

Dernbach, J., (1998), Sustainable development as a framework for national governance, Case Western Reserve Law Review, Vol. 49, no. 1, pp. 1-103.

Dobson, A., (1996), Environmental Sustainabilities: an analysis and a typology, Environmental Politics, Vol. 5, pp. 401-428.

Duran, D., Artene, A., Gogan, L., Duran, V., (2015), The Components of Sustainable Development A Possible Approach, Procedia Economics and Finance. Vol. 26, pp. 806-811.

Duran, D., Artene, A., Gogan, L., Duran, V., (2015), The Objectives of Sustainable Development Ways to Achieve Welfare, Procedia Economics and Finance. Vol. 26, pp. 812-817.

Ekins, P., Simon, S., Deutsch, L., Folke, C., De Groot, R., (2003), A Framework for the practical application of the concepts of critical natural capital and strong sustainability, Ecological Economics, Vol. 44, no. 3, pp. 165-185.

Elkington, J., (1994), Towards the Sustainable Corporation: Win-Win-Win Business Strategies for Sustainable Development, California Management Review, Vol. 36, no. 2, pp. 90-100.

Emas, R., (2015), Brief for GSDR 2015 The Concept of Sustainable Development : Definition and Defining Principles, Florida International University, pp. 1-3.

Feil, A., Schreiber, D., (2017), Sustainability and sustainable development: unraveling overlays and scope of their meanings, Cadernos, Vol. 14, no. 3, pp. 667-681.

Fergus, H., Rowney, J., (2005), Sustainable Development: Lost Meaning and Opportunity?, Journal of Business Ethics. Vol. 60. pp. 17-27.

Harlow, J., Golub, A., Allenby, B., (2013), A review of utopian themes in sustainable development discourse, Sustainable Development, Vol. 21, no. 4, pp. 270-280.

Harwood, R., (1990), The history of sustainable agriculture, In C.A. Edwards et al. (Eds.), Sustainable Farming Systems, pp. 3-19.

Holden, E., Linnerud, K., Banister, D., (2014), Sustainable development: Our Common Future revisited, Global Environmental Change, Vol. 26, no. 1, pp. 130-139.

Hove, H., (2004), Critiquing Sustainable Development: A Meaningful Way of Mediating the Development Impasse, Undercurrent, Vol. 1, no. 1, pp. 48-54.

Hoyer, K. (2000): Sustainable Mobility - The Concept of Its Implications, Western Norway Research Institute, Sogndal.

Ivascu, L. (2013): Contribuții privind managementul riscului în întreprinderea sustenabilă, Editura Politehnica, Timisoara. 
Jabareen, Y., (2008), A new conceptual framework for sustainable development, Environment, Development and Sustainability, Vol. 10, no. 2, pp. 179-192.

Kates, R., Parris, T., Leiserowitz, A., (2005), What is Sustainable Development? Goals, Indicators, Values and Practice, Environment: Science and Policy for Sustainable Development, Vol. 47, no. 3, pp. 8-21.

Klarin, T., (2018), The Concept of Sustainable Development: From its Beginning to the Contemporary Issues, Zagreb International Review of Economics and Business, Vol. 21, no. 1 , pp. 67-94.

Lélé, S., (1991), Sustainable development: a critical review, World Development, Vol. 19, pp. 607621.

Marin, C., Dorobanțu, R., Codreanu, D., Mihaela, R., (2012), The Fruit of Collaboration between Local Government and Private Partners in the Sustainable Development Community Case Study: County Valcea, Economy Transdisciplinary Cognition, Vol. 2, pp. 93-98.

Meadows, D. (2004): The Limits of Growth, Chelsea Green Publishing, White River Junction, VT.

Mebratu, D., (1998), Sustainability and sustainable development: historical and conceptual view, Environmental Impact Assessment Review, Vol. 18, pp. 493-520.

Morris, M., (2012), Sustainability: An Exercise in Futility, International Journal of Business and Management, Vol. 7, no. 2, pp. 36-44.

Naess, A., (1988), The Basics of Deep Ecology, Resurgence, pp. 47-62.

National Research Council. (1999): Our Common Journey: A Transition Toward Sustainability, The National Academies Press, Washington, DC.

Newton, J., Freygole, E., (2005), Sustainability: a dissent, Conservation and Biology, Vol. 19, no. 1, pp. 23-32.

O'Riordan, T. (1996): Environmentalism on the move in Douglas, I., Huggett, R. and Robinson, M. (Eds.), Companion encyclopaedia of geography, Routledge, London.

Prugh, T., Assadourian, E., (2003), What is sustainability, anyway?, World Watch, Vol. 16, no. 5, pp. 10-21.

Pearce, D. (1989): Tourism Development, Harlow, London.

Redclift, M., (2006), Sustainable development (1987-2005)-an oxymoron comes of age, Horizontes Antrolopogicos, Vol. 12, no. 25, pp. 65-84.

Sartori, S., Campos, L., Latrônico, F., (2014), Sustainability and sustainable development: A taxonomy in the filed of literature, Ambiente \& Sociedade, Vol. 17, no. 1, pp. 1-20.

Slimane, M., (2012), Role and relationship between leadership and sustainable development to release social, human, and cultural dimension, Social and Behavioral Sciences, Vol. 41, pp. 92-99.

Sterling, S., (2010), Learning for resilience, or the resilient learner? Towards a necessary reconciliation in a paradigm of sustainable education, Environmental Education Research, Vol. 16, pp. 511-528.

Vander-Merwe, I., Van-der-Merwe, J. (1999): Sustainable development at local level: An introduction to local agenda 21, Pretoria: Department of environmental affairs and tourism.

Waas, T., Hugé, J., Verbruggen, A., Wright, T., (2011), Sustainable Development: A Bird's Eye View, Sustainability. Vol. 3. pp. 1637-1661.

WCED - World Commission on Environment and Development. (1987): Our Common Future, Oxford University Press, Oxford.

Williams, C., Millington, A., (2004), The diverse and contested meanings of sustainable development, Geographical Journal, Vol. 170, no. 2, pp. 99-104.

Yolles, M., Fink, G., (2014), The Sustainability of Sustainability, Business Systems Review, Vol. 3, no. 2, pp. 1-32. 